\title{
Taxing Large Businesses: Cooperative Compliance in Action
}

It is well recognised that large business taxpayers are qualitatively different from other categories of taxpayers; they make a significant contribution to tax revenues collected in most countries and therefore pose a signifi-

Lotta Björklund Larsen, Tax Administration Research Centre, University of Exeter, UK.

Lynne Oats, Tax Administration Research Centre, University of Exeter, UK. cant risk to tax administration effectiveness. Large businesses, particularly multinational enterprises (MNEs), are also different from other taxpayers because of their

(C) The Author(s) 2019. Open Access: This article is distributed under the terms of the Creative Commons Attribution 4.0 International License (https://creativecommons.org/licenses/by/4.0/), which permits unrestricted use, distribution, and reproduction in any medium, provided you give appropriate credit to the original author(s) and the source, provide a link to the Creative Commons license, and indicate if changes were made.

* The research leading to these results has received funding from the European Union's Horizon 2020 research and innovation programme 2014-2020, grant agreement No. FairTax 649439. 
complex operations and structure. From the late 1990s into the 2000s, it became clear that there was a need for new strategies for managing large business taxpayers; by 2005, what later became known as 'cooperative compliance' strategies began to emerge in several countries. Cooperative compliance represents a shift in thinking for tax administrations, away from a deterrence approach where taxpayers are coerced to comply with tax rules and threatened by audits and penalties, toward a more responsive and collaborative approach.

There is evidence of benefits of cooperative compliance for both taxpayers and tax administrations: quicker responses to questions, less uncertainty in tax positions as questionable tax issues would be resolved before reporting, fewer issues to be decided in court, the diminishing need for lengthy tax audits and increasing legal certainty and predictability. As a result, administrative costs for the tax administration and compliance costs for taxpayers are expected to decrease. In short, there are many efficiency gains. But there have also been warnings that such gains could be too short-sighted. The efficiency aspect is questioned more broadly: the possible short-term gains from cost-effectiveness and shortened response time for questionable tax issues could be lost in the longer term due to corporations' decreased compliance. Corporations also question the efficiency if they face additional extra workload. Does cooperative compliance mean that tax administrations effectively outsource control to those who are supposed to be controlled?

Given the various opinions and concerns about cooperative compliance, it was timely to investigate how these programmes work out in practice. While taxation has most often been researched using legal or quantitative approaches, qualitative and ethnographically inspired studies of tax administration and taxation are increasingly in demand. ${ }^{1}$ Taxation is a complicated issue and we need improved understanding of how policies are adapted in practice and how taxpayers respond to them. ${ }^{2}$ There exists a number of analyses which - implicitly or explicitly - compare coop-

1 M. Lamb, A. Lymer, J. Freedman, S. James: Taxation: An Interdisciplinary Approach to Research, Oxford 2005, Oxford University Press; J. Alm: Measuring, explaining, and controlling tax evasion: lessons from theory, experiments, and field studies, in: International Tax and Public Finance, Vol. 19, No. 1, 2012, pp. 54-77; L. O ats (ed.): Taxation: A Fieldwork Research Handbook, London and New York 2012, Routledge; C. Peters: On the legitimacy of international tax law, Amsterdam 2014, IBFD; D. Ring: The promise of international tax scholarship and its implications for research design, theory and methodology, in: St. Louis University Law Journal, Vol. 55, No. 1, 2010, pp. 307-330.

2 S. Steinmo: The Leap of Faith: The Fiscal Foundations of Successful Government in Europe and America, Oxford 2018, Oxford University Press. erative compliance programmes from a legal perspective ${ }^{3}$ and from a more policy inspired approach. ${ }^{4}$ While there are many insights to be gained from these studies, they do not address how cooperative compliance actually works in practice. This is where our research makes a contribution.

The aim of this article is thus twofold. First, we present key features of the cooperative compliance model in its practical implementation and operation. Second, we go beyond national comparisons and propose seven dimensions of practice based on a qualitative comparison of cooperative compliance programmes in selected jurisdictions. These universal dimensions ought to be considered when implementing or changing cooperative compliance programmes in any jurisdiction.

\section{Method}

This article builds on research conducted over several years in Northern Europe (in Denmark, ${ }^{5}$ Finland, ${ }^{6}$ the Netherlands, ${ }^{7}$ Norway, ${ }^{8}$ Sweden ${ }^{9}$ and the $\mathrm{UK}^{10}$ ) engaging

3 K. Bronzewska: Co-operative compliance. A new approach to managing taxpayer relations, Amsterdam 2016, IBFD; R. Szudoczky, A. Majdanska: Designing Co-operative Compliance Programmes: Lessons from the EU State Aid Rules for Tax Administrations, in: British Tax Review, Vol. 2017, No. 2, 2017.

4 OECD: Co-operative Compliance: A Framework. From Enhanced Relationship to Cooperative Compliance, Paris 2013, OECD Publishing; L.G.MStevens, M. Pheijffer, J.G.A. van den Broek, T.J. Keijzer, L. van der Hel-van Djik (eds.): Tax supervision - Made to measure, The Hague 2012, Committee Horizontal Monitoring Tax and Customs Administration.

5 See K. Boll, M. Brehm Johansen: Tax Governance: Corporate experiences with Cooperative Compliance in Denmark, Fairtax Working Paper No. 17, Umeå 2018, Umeå Universitet; K. Boll: Securing Tax Compliance with Collaboration: The Case of Cooperative Compliance in Denmark, in: N. Hashimzade, Y. Epifantseva (eds.): The Routledge Companion to Tax Avoidance Research, Abingdon 2018, Routledge, pp. 212-224.

6 T. Potka-Soininen, J. Pellinen, J. Kettunen: Enhanced Customer Cooperation: Experiences with cooperative compliance in Finland, Fairtax Working Paper No. 19, Umeå 2018, Umeå Universitet.

7 D. De Widt: Dutch Horizontal Monitoring: The Handicap of a Head Start, Fairtax Working Paper No. 13, Umeå 2017, Umeå Universitet.

8 B. Brøgger, K. Aziz: The setting for collaboration about tax compliance in Norway, Fairtax Working Paper No. 18, Umeå 2018, Umeå Universitet.

9 L. Björklund Larsen: Sweden: failure of a cooperative compliance project?, Fairtax Working Paper No. 7, Umeå 2016, Umeå Universitet; L. Björklund Larsen: What Tax Morale? A moral anthropological stance on a failed co-operative compliance initiative, in: Journal of Tax Administration, Vol. 5, No. 1, 2019, pp. 26-40; L. Björklund Larsen: Sweden: Failure of a Cooperative Compliance Project?, in: E. Mulligan, L. Oats (eds.): Contemporary Issues in Tax Research, Vol. 3, Birmingham 2018, Fiscal Publications, pp. 7-50.

10 L. Oats, D. De Widt: Co-operative Compliance: The UK case playing the long game, Fairtax Working Paper No. 22, Umeå 2019, Umeå Universitet; see also D. De Widt, L. Oats, E. Mulligan: The US Compliance Assurance Process: A relational signalling approach, in: Journal of Tax Administration, Vol. 5, No. 1, 2019, pp. 120-136; D. De Widt, L. Oats: Cooperative Compliance in Action: A UK/Dutch Comparison, in: E. Mulligan, L. Oats (eds.): Contemporary Issues in Tax Research, Vol. 3, Birmingham 2018, Fiscal Publications, pp. 260-277. 
with all stakeholders in the corporate tax arena. We used ethnographic techniques, primarily in-depth interviews, to investigate how developments in each jurisdiction are playing out in practice. In each country, the actors interviewed include large business in-house tax specialists, external advisors and industry representative bodies as well as tax authority large business specialists. In addition, we have collected and analysed policy documents, media reports and other documents addressing cooperative compliance projects in each country.

The comparison of cooperative compliance models in these countries, often considered quite similar, is instructive: in the variations shown in the adaptation of the model, in the responses they drew from stakeholders and in the resulting legacy of the model that will continue to shape relations between tax administrations and large corporations. The Netherlands and the UK share a historical similarity in their approach to tax administration. These two countries were early adopters of cooperative compliance models, yet the models they adopted are quite different. In the Nordic countries, which adopted similar cooperative compliance at a later stage, the outcomes were very different. In all countries, the history of previous collaboration and the external environment have been influential in shaping the trajectory of cooperative compliance. For some countries, cooperative compliance was a radical change; for others, it was a slight modification of a model that had already been implemented. As this research shows, past experiences and relations established between tax administrations and large businesses have a significant impact on how the programmes unfolded.

\section{Background}

Forerunners in developing cooperative compliance projects were the Netherlands, Ireland, the UK and the US. The OECD took on an active role in promoting the benefits of cooperative compliance and most of its member states' tax administrations have now implemented their own adaptation of the model. This process has been facilitated by support for the model from many large business taxpayers across jurisdictions.

Cooperative compliance builds on the slogan: "certainty in exchange for transparency". ${ }^{11}$ It is a proactive approach that aims to enhance tax compliance before tax statements are delivered and legal control systems take over. There is no universal cooperative compliance model, however, three common features include:

11 OECD: Co-operative Tax Compliance: Building Better Tax Control Frameworks, Paris 2016, OECD Publishing.
- Risk assessment: more sophisticated risk assessment procedures allow for the identification of taxpayers requiring closer monitoring by the tax authority and those who can be trusted to be compliant and/or have more simple business operations and therefore warrant less close monitoring: ${ }^{12}$

- Real-time working: cooperative compliance models generally facilitate real-time working and avoid waiting for tax returns to be filed followed by an audit/examination, protracted information requests and dispute resolution. Corporate taxpayers bring tax issues to the attention of the tax authority as they are happening, in advance of filing, in order to discuss and hopefully agree on the tax position and prevent unnecessary inquiries and disputes; and

- Mutual understanding: tax authorities with cooperative compliance models generally commit resources to upskilling tax officials so that they are better equipped to understand the complexities and context of large corporate taxpayers and have frequent engagement with them. In return for increased certainty about the tax consequences, taxpayers are expected to be transparent about their activities.

\section{Key features of implementation and operation}

Over the years, as more and more countries have introduced cooperative compliance models, it has become possible to identify key features of their implementation and practical operation. Table 1 shows which of these key features are included in the cooperative compliance programmes in the six countries studied.

Implementation

- Pilot: in some countries, a formal pilot programme has been introduced to test the model before becoming widely available;

- Explicitness: the model may or may not be explicitly described as a cooperative compliance arrangement;

- Legislative change: some models of cooperative compliance require changes in laws and regulations to enable implementation. In others, the model is embedded within the existing legal framework;

12 For a UK/Netherlands comparison of risk assessment processes see D. De Widt, L. O ats: Risk Assessment in a Cooperative Compliance Context: A Dutch-UK Comparison, in: British Tax Review, Vol. 2017, No. 2, 2017, pp. 230-248. 
Table 1

Key features of the cooperative compliance model

\begin{tabular}{|c|c|c|c|c|c|c|}
\hline & Denmark & Finland & Netherlands & Norway & Sweden & UK \\
\hline \multicolumn{7}{|c|}{ Implementation } \\
\hline Pilot & $\sqrt{ }$ & $\sqrt{ }$ & & $\sqrt{ }$ & & \\
\hline Explicitness & $\sqrt{ }$ & $\sqrt{ }$ & $\sqrt{ }$ & & $\sqrt{ }$ & \\
\hline \multicolumn{7}{|l|}{$\begin{array}{l}\text { Legislative } \\
\text { change }\end{array}$} \\
\hline Formality & $\sqrt{ }$ & $\sqrt{ }$ & & & $\sqrt{ }$ & \\
\hline $\begin{array}{l}\text { Voluntary } \\
\text { participation }\end{array}$ & $\sqrt{ }$ & $\sqrt{ }$ & $\sqrt{ }$ & $\sqrt{ }$ & $\sqrt{ }$ & \\
\hline $\begin{array}{l}\text { Inclusiveness } \\
\text { (all large } \\
\text { businesses) }\end{array}$ & & & & & & $\sqrt{ }$ \\
\hline \multicolumn{7}{|l|}{ Operation } \\
\hline $\begin{array}{l}\text { Single point } \\
\text { of contact }\end{array}$ & $\sqrt{ }$ & $\sqrt{ }$ & $\sqrt{ }$ & $\sqrt{ }$ & $\sqrt{ }$ & $\sqrt{ }$ \\
\hline $\begin{array}{l}\text { Provision of } \\
\text { advance } \\
\text { rulings }\end{array}$ & $\sqrt{ }$ & $\sqrt{ }$ & $\sqrt{ }$ & & & \\
\hline
\end{tabular}

Source: Authors' own compilation.

- Formality: may be in the form of a formal legal agreement, a more informal memorandum of understanding or an informal arrangement with undocumented elements;

- Participation: may be voluntary or compulsory. In some countries, participation is voluntary, in others by invitation from the tax authority; and

- Inclusiveness: in some countries all large businesses are part of the programme, in others only a selection is included, leaving some outside of the model.

\section{Operation}

- Single point of contact: most models provide for a single point of contact with the relevant large taxpayer unit; and

- Provision of advance rulings: where applicable, the provision by the tax authority of advance rulings as to the tax outcome of large business' activities may or may not be binding on the tax authority.

\section{Dimensions of practice}

These dimensions are based on comparisons between the countries developed in an inductive manner from the empirical material. Our approach to comparison is in- spired by anthropology, ${ }^{13}$ selecting various cases strategically in order to achieve the greatest possible amount of information on a given problem. ${ }^{14}$ We maintain our focus on how compliance programmes were applied in practice and how they impact existing relations between actors in the national tax arenas.

\section{Cultural orientation}

Cooperative compliance programmes have resulted in cultural reorientations. These can be seen in terms of time and space as well as relationships to some extent in all the studied countries. The timing of interactions between large businesses and tax authorities under cooperative compliance shifts from regular spaced events such as filing returns, to more irregular needs-based interactions. Spatial changes include the creation of new or reorganised large taxpayer units. Relationships shift from a command and control, coercive style to a collaborative and more consensual approach. In the case of Denmark, Finland and the Netherlands, we find the introduction of new principles and routines working according to the cultural orientation. In Norway, the main concern was temporal reorientation. Each taxpayer had to work out the meaning of a number of changes individually. In Sweden, the spatial reorientation evoked strong reactions in the absence of a strong collaborative tradition. In the UK, the cultural reorientation was much more gradual and therefore muted.

\section{Evaluation}

The evaluation of cooperative compliance programmes against the criteria of effectiveness and efficiency is very difficult in all cases. It is problematic to try to find a point of comparison in order to determine what the outcomes would have been without cooperative compliance. Therefore, it is difficult to infer which outcomes are attributable to the cooperative compliance model and which are overall attributable to the tax administration's actions. Based on the data collected for the present research, it is not possible to say whether the use of tax administrations' resources in any of the countries is more efficient than before or that cooperative compliance has brought about direct cost savings.

13 M. Schnegg: Anthropology and Comparison: Methodological Challenges and Tentative Solutions, in: Zeitschrift für Ethnologie, Vol. 139, No. 1, 2014, pp 55-72; P. van der Veer: The Value of Comparison, Durham and London 2016, Duke University Press.

14 B. Flyvbjerg: Five misunderstandings about case-study research, in: Qualitative Inquiry, Vol. 12, No. 2, 2006, pp. 219-245. 


\section{Competences}

The requirement for changed competences as a result of cooperative compliance was articulated differently both between countries and between stakeholders e.g. between corporations and the tax administrations. First, corporations in all six countries expressed the belief that tax officials lack knowledge about business and commercial reality. Secondly, additional or 'new' knowledge required by tax officials varied by country: in Denmark, it was the skill to resolve conflicts; in Finland, providing good customer service; in Sweden, being a 'people person' and in the Netherlands as well as in the UK, officials were expected to have 'commercial awareness' and be able to 'avoid disputes'. There were also issues raised as to who should be responsible for building competences within the tax administrations.

\section{Hindrances}

We find similar kinds of hindrances in all six cases, some of which are external and structural, while others are internal and organisational. External structural hindrances include legal issues such as public access to documents, equality and the possibility of attaining binding responses from the tax administration. They also include more diffuse hindrances such as increased public scrutiny. The internal organisational hindrances, such as different but coexisting 'schools of thought' and internal discussions on impartiality in the tax administration, challenge the work with the cooperative compliance programme. The comparisons showed that legal matters can come to impede a programme. If the external structural hindrances become too large to overcome, the cooperative compliance programmes might not even get so far as to be faced with internal organisational hindrances, as was the case in Sweden. The effect of increased public scrutiny has been felt more acutely in the Netherlands and the UK. The internal organisational hindrances are more subtly shaping the way the programmes unfold.

\section{Resistance}

Outspoken resistance has played a minor role in the implementation of cooperative compliance measures in some of the countries. In the case of Denmark, Finland and Norway the most apt description of the stance of the corporations is 'voice' and 'loyalty'. ${ }^{15}$ It can be characterised by the co-existence of silent resistance - declining an invitation to participate or postponing letters and meetings, and loyalty - to stay in place and cope in either

15 A. Hirschman: Exit, voice and loyalty. Responses to decline in firms, organizations and states, 1970, Harvard University Press. a proactive way or more passively by accepting the premises but not leading in the collaboration. In the Netherlands, resistance is manifest in a failure to apply to join the programme. In Sweden the stance was 'voice' and 'exit', which stalled the implementation of the cooperative compliance programme. In the UK, because the programme is compulsory for all large businesses, less overt forms of resistance include the continuation of old practices of withholding information from tax authorities leading to new legislative measures more aligned with coercive relationships.

\section{Trust}

Trust is widely recognised as being essential in building enduring cooperative compliance programmes and relationships between tax administrations and corporations. ${ }^{16}$ In all six countries, the dominant form of trust appeared to be the inter-organisational trust. In most cases trust seems to persist even if the individuals on either side of the relationship change. There were differences between the countries as to the types of trust, however. The interpersonal trust between the tax officials and tax directors in the corporations plays a significant role, especially in the Danish, Finnish and UK cases. Nonetheless, as the case of Sweden shows, a high level of measured trust towards tax administrators is not a guarantee of a successful cooperative compliance approach. In the Netherlands, resource constraints in the tax authority appear to lead to the erosion of large business' trust in the system.

\section{Equality}

The last dimension shows that there was a substantial variation between the countries with regard to fair competition and equality. In Norway, it was not problematic because the tax law is structured according to industrial sectors, which means that corporations accept that different industries might be subject to different treatment. In Denmark, the discussion focused on potential favourable treatment of corporations and it was pronounced in terms of consultancy vs. guidance. The first type of activity, consultancy, is not allowed for tax officials of Skat, ${ }^{17}$ whereas the latter activity, guidance, is. In the context of the Finnish Syvennetty, discussion about unequable treatment has been limited. In Sweden, the discussion of inequitable treatment was one of the major obstacles to both versions of the programme. The very idea of a VIP

16 See for example J. Freedman: Restoring Trust in the 'Fairness' of Corporate Taxation: Increased transparency and the need for institutional reform, in: S. Gosling a et al. (eds.): Trust and Taxation: Institutions, Interactions and Instruments, Amsterdam 2018, Eleven.

17 Skat stands for Skatteforvaltningen, the Danish customs and tax administration. 
lane for certain 'customers' in public bureaucracy was not well received by Swedish society. In the Netherlands, the external perception that Horizontal Monitoring comprises an exchange of illegitimate favours leads to speculation that it would not be possible to implement it now. In the UK, the model applies to all large businesses and there is equal treatment within that category of taxpayer; nevertheless, public concern persists that large businesses as a whole are treated more favourably by HMRC..$^{18}$ Our six country cases diverge most strongly when it comes to the dimension of equal treatment.

\section{Conclusion}

The aim of this research project was to draw comparisons from beyond the typical aspects of the various 'models of cooperative compliance' - including national tax laws, policies and guidelines, the number of participants or size of participating corporations, the year of introduction and similar factual dimensions. We have taken inspiration from anthropological studies: we accounted for the views of a broad range of stakeholders in the tax arena; we were interested in the programmes' outcome in practice; and we see taxation as creating relations. ${ }^{19}$

The seven dimensions we propose - cultural orientation, evaluation, competences, hindrances, resistance, trust and equality - are not mutually exclusive, but are defined in such a way that there are possible overlaps between them. Such an analytical approach is a strength as it allows the analysis to capture more nuances and diversity in the material than would a less generous and more limited taxonomy. These seven dimensions are not ordered in hierarchical importance. Yet some of the dimensions show substantial differences between the countries, whereas other dimensions reveal more similar insights.

We offer three concluding remarks. The first is that a number of cultural, institutional and societal factors influence compliance practices. As mentioned above, a major trend in tax administration has been to shift from a roughly onesize-fits-all approach - where almost all taxpayers experience a deterrence approach - to a responsive approach where various segments of taxpayers receive treatment according to their motivational postures on compliance. That is a foundational principle of the OECD cooperative compliance guidelines. The measures are founded on the idea that the will of the individual is the decisive factor for tax compliance. In this report, the comparison between

18 HMRC stands for Her Majesty's Revenue and Customs, the UK's tax, payments and customs authority.

19 See S. Steinmo, op. cit. actual practices in these six countries provides evidence that a number of cultural, institutional and societal factors also influence compliance practices. In other words, tax compliance does not only depend on the will of taxpayers. It is equally shaped by the actual interaction between the taxpayer and the tax administration as well as by contextual factors. When other factors are taken into consideration, as they frequently are in actual practice, other venues for cooperation and responsiveness open up. The aim of a more responsive tax administration becomes more attainable than when the only course of action is to influence the taxpayers' will.

The second remark is that other key principles of the OECD guidelines - namely voluntary disclosure and realtime responses - are too narrow and perhaps too idealistic to be feasible guidelines for all circumstances when compliance is mitigated. The OECD also defines cooperative compliance as a regulatory approach building on the idea that participating corporations disclose relevant information including their tax risks and are transparent with the tax administrations. In return, tax administrations are to provide real-time predictability and clarity on taxation issues of relevance for the corporation. ${ }^{20}$ Our research shows that real-time responses are neither welcome nor possible under all circumstances. It is actually more crucial to be explicit about a change in the timeframe than to have all interactions in real time.

Finally, there is a growing need in all countries for reliable evaluation mechanisms. A key ambition for the cooperative compliance measures has been to increase efficiency and effective use of resources for tax administration and many stakeholders demand 'proof' of efficient resource usage, especially the taxpayers themselves. All countries are facing the difficulty of measuring the impact of these programmes. Increased knowledge exchange between tax authorities would be beneficial for further developing the programmes and evaluating their effects. In actual practice, such evaluations of costs and effects need to combine subjective and objective criteria, statistical analysis, logical argument, common sense, human skills and judgement.

We find considerable learning between jurisdictions as well as a significant heterogeneity in the local implementation of these models. This has implications for countries considering adopting cooperative compliance models, as we have seen that what works well in one jurisdiction may not necessarily translate into efficiencies in another.

20 OECD, op. cit. 